This article was published in European Journal of Wood and Wood Products, 72, 117121, 2014

http://dx.doi.org/10.1007/s00107-013-0761-9

\title{
The influence of scavengers on VOC emissions in particleboards made from pine and poplar
}

\author{
N. A. Costa $\bullet$ M. Ohlmeyer • J. Ferra $\bullet$ \\ Fernão D. Magalhães • A. Mendes •
}

L. Carvalho

N. A. Costa, F. D. Magalhães, A. Mendes, L. Carvalho LEPAE-Laboratório de Engenharia de Processos, Ambiente e Energia, Faculdade de Engenharia, Universidade do Porto, Rua Dr. Roberto Frias, 4200-465 Porto, Portugal

N. A. Costa, J. Ferra

EuroResinas-Indústrias Químicas, S.A., Sines, Portugal

N. A. Costa

ARCP-Associacão Rede de Competências em Polímeros, Porto, Portugal

M. Ohlmeyer (\&)

Thu"nen-Institute of Wood Research, Leuschnerstrasse 91c, 21031 Hamburg, Germany e-mail: martin.ohlmeyer@ti.bund.de

L. Carvalho

DEMad-Departamento de Engenharia de Madeiras, Instituto Politécnico de Viseu, Campus Politécnico de Repeses, 3504-510 Viseu, Portugal

Abstract This paper studies the performance of scavengers on Volatile Organic Compound (VOC) emissions from wood-based composites. Particleboards made from maritime pine (Pinus Pinaster Ait.) and European poplar (Populus spp.) were produced with a UF resin doped with melamine and two scavengers, sodium metabisulfite and urea. VOC emission was measured according to EN ISO 16000. Particleboards made from pine present much higher total VOC (TVOC) emissions than boards made from poplar. Pine emits a higher amount of terpenes, but also aldehydes, acids and terpenoids, while poplar emits mainly acetic acid. Sodium metabisulfite showed an excellent ability to reduce aldehydes emission, which represents nearly $50 \%$ of total emission of particleboards made from pine. When sodium metabisulfite was applied to particleboards made from poplar, reduction of TVOCs was not significant due to the low contribution of aldehydes to TVOCs. Urea presents a low reduction in TVOCs for both wood species. 


\section{Introduction}

Pinus Pinaster Ait. is one of the most common softwoods in Portugal, corresponding to more than $75 \%$ of the total consumption of the sawmill industry (AIMMP 2013) and also widely used in the production of particleboards (usually combined with other wood types, mainly eucalypt (Eucalyptus globulus) and recycled wood) (Martins et al. 2007). In natural stands, the genus Populus is generally represented by several species. Populus nigra and Populus alba are the most common ones in Iberia Peninsula (Carvalho 1997).

In the last decades, there is an increasing concern over indoor air quality. Wood raw-material for wood based-panels is an important biological source of VOC, especially isoprene and terpenes in case of natural wood. In case of recycled wood, depending on the level of contamination, there are contributions from other sources, like adhesives, impregnated paper, paints, wax, lacquers and wood preservatives. The frequent use of wood-based panels in house construction can often lead to elevated VOC concentration, mainly of terpenes and aldehydes (Hodgson et al. 2002). VOC emissions from wood-based panels depend on production parameters, such as pressing time and temperatures, surface structure and storage conditions (Makowski and Ohlmeyer 2006a; Ohlmeyer et al. 2008).

The release of VOCs can be measured in test chambers with $1 \mathrm{~m}^{3}$, however, studies carried by Makowski and Ohlmeyer (2006b) showed that minimal differences can be found in VOCs emission between tests carried in large $\left(1 \mathrm{~m}^{3}\right)$ and small $(23.5 \mathrm{~L})$ chambers.

Wood contains several free compounds in its interlinked main cell wall constituents. Softwoods are usually rich in extractives and therefore can release substantial amounts of VOCs, mainly terpenes and aldehydes (Fengel and We-gener 1989). Terpenes and acids are strongly dependent on wood species, while formaldehyde is mainly related to the adhesive. Other aldehydes are formed under certain conditions by autoxidative splitting of free unsaturated fatty acids and triglycerides (Makowski and Ohlmeyer 2006a; Fischer and Aehlig 2007; Steckel et al. 2010). Makowski et al. (2005) and Makowski and Ohlmeyer (2006a) observed an increase in aldehydes emission during the first days, followed by a decrease in the last week. Terpenes are essential components for defence against insects and fungi and occur naturally in softwood oleoresin. Due to their relatively high vapour pressure at ambient temperatures, terpenes are volatile and contribute to the characteristic odour of different wood species (Makowski and Ohlmeyer 2005; Fengel and Wegener 1989). Hardwoods release mainly a high amount of acetic and formic acid and less terpene compounds (Risholm-Sundman et al. 1998).

In the last decades, several studies using formaldehyde scavengers have been published (Eom et al. 2006; Kim et al. 2006; Kim 2009; Costa et al. 2013a, b), as well as on resin synthesis optimization for low formaldehyde emission wood-based panels (Ferra et al. 2010; Costa et al. 2012; Paiva et al. 2012), some of them with notable success, reaching formaldehyde emission near solid wood level and also zero emission. Some innovative works studied new formaldehyde-free adhesives, but their difficult application (Prasittisopin and Li 2010) and low reactivity (Despres et al. 2010; Tang et al. 2011) lead to high pressing times and lower productivity, having no acceptance in the industry. 
In the last years, the emission issues have focused on VOCs. Germany and France were pioneers on VOC regulations. No mandatory upper limits are established yet.

This paper evaluates the performance of formaldehyde scavengers (urea and sodium metabisulfite) on VOC emissions from particleboards made from two different wood species (pine and poplar). VOCs were collected in Tenax tubes, measured according to EN ISO 16000-6, during 28 days in a $23.5 \mathrm{~L}$ chamber and evaluated using a GC-MS. It must be noted that Tenax does not adsorb formaldehyde. Therefore this analysis does not account for formaldehyde emission from the resin. Only larger aldehydes and other VOCs, coming solely from the wood species, are quantified.

\section{Materials and methods}

\subsection{Materials}

A last generation commercial UF resin was provided by EuroResinas-Indústrias Químicas, S. A. (Sines, Portugal). Maritime pine (Pinus Pinaster Ait.) particles were supplied by Sonae Indústria PCDM, S.A. (Oliveira do Hospital, Portugal) and poplar (Populus spp.) particles were supplied by Sonae Indústria Tradema S.L. (Linares). Scavengers were provided by EuroResinas (urea) and purchased from Vaz Pereira, S.A. (Lisbon, Portugal) (sodium metabisulfite).

\subsection{Methods}

\subsubsection{Particleboard production}

Wood particles were blended with resin, paraffin and catalyst (ammonium nitrate) in a laboratory glue blender. For all trials, the resin load was kept constant ( $8 \%$ based on oven dry wood). Face and core layer differ in the final moisture content (11 and $8 \%$, respectively) and catalyst content ( 1 and $3 \%$, respectively, based on solid resin). Sodium metabisulfite in powder form was spread after the blending operation. Solid urea (prills) used in core layer was spread after the blending operation while in the face layer a $30 \%$ solution was added prior to blending operation. Particleboards were hand formed into a square shape with $50 \mathrm{~cm}$ by side achieving a wood mass distribution of $20 \%$ in the upper face layer, $60 \%$ in the core layer and $20 \%$ in the bottom layer. Boards were pressed at $190^{\circ} \mathrm{C}$ for $160 \mathrm{~s}$.

\subsubsection{VOC evaluation}

2.2.2.1 Equipment and chamber operation (according to EN ISO 16000-9) Equipment, sampling as well as analytical procedures were according to EN ISO 16000 part 6 (2011) and part 9 (2006). Glass desiccators ( $23.5 \mathrm{~L}$ ) were used as emission test chamber. Air exchange rate of $3.1 \mathrm{~h}^{-1}$ was kept constant as well as temperature and relative humidity $\left(23^{\circ} \mathrm{C}\right.$ and $\left.50 \%\right)$. Sample area related to chamber volume was $3.1 \mathrm{~m}^{2} \mathrm{~m}^{-3}$. Air samples (2-4 $\mathrm{L}$ ) were pumped on the $1 \mathrm{st}, 3 \mathrm{rd}, 7 \mathrm{th}, 21 \mathrm{st}$ and 28th day from the test chambers. VOCs were collected in metallic tubes filled with Tenax TA.

2.2.2.2 Analytical procedure (according to EN ISO 16000-6) Compounds identification and quantification was performed in a gas chromatograph (Agilent 6895), coupled with a thermal 
desorption unit (Markes, UK) and a mass spectrometer (Agilent 5973N). Limit of quantification considered was $5 \mu \mathrm{g} \mathrm{m}^{-3}$. Emission results are expressed as concentration $\mathrm{C}$ of compounds in chamber air $\left(\mu \mathrm{g} \mathrm{m}^{-3}\right)$. Due to the selected loading factor and air exchange rate as well as the relatively slow decay of the concentration over time, the results can also be read directly as areaspecific emission rates (emission factors, SERa in $\mathrm{mg} \mathrm{m}^{-2} \mathrm{~h}^{-1}$ ), according to ECA report no. 18 (1997). TVOC mean total VOC emission in the air sample. It is calculated by adding the concentrations of all single compounds detected in that air sample.

\section{Results and discussion}

Figure 1 shows emission from particleboards made from pine. It can be observed that aldehydes emission increased with time, presenting a small reduction after 28 days. This behaviour has already been reported by Makowski et al.(2005) and Makowski and Ohlmeyer (2006a) and could be related to oxidation of fatty acids. A small reduction of aldehydes emission is visible when urea is used. However, after 28 days, this difference is negligible. Aldehydes released are mainly hexanal, but pentanal, nonal, octanal and heptanal are also found. When sodium metabisulfite is used, the reduction is substantial, showing the excellent ability of sodium metabisulphite to scavenge a wide range of aldehydes. The amount of acids (acetic) release was kept stable during the testing period and no significant differences in acid emission can be found when scavengers were used.
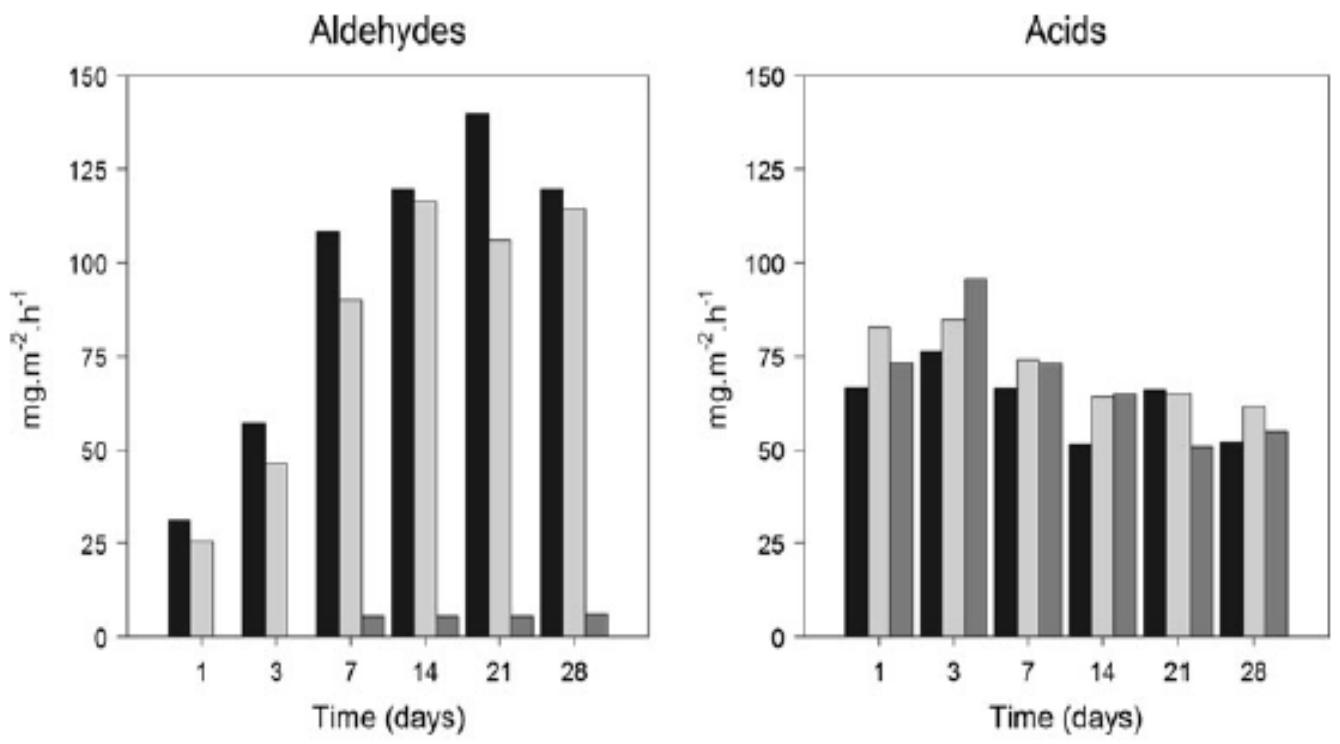

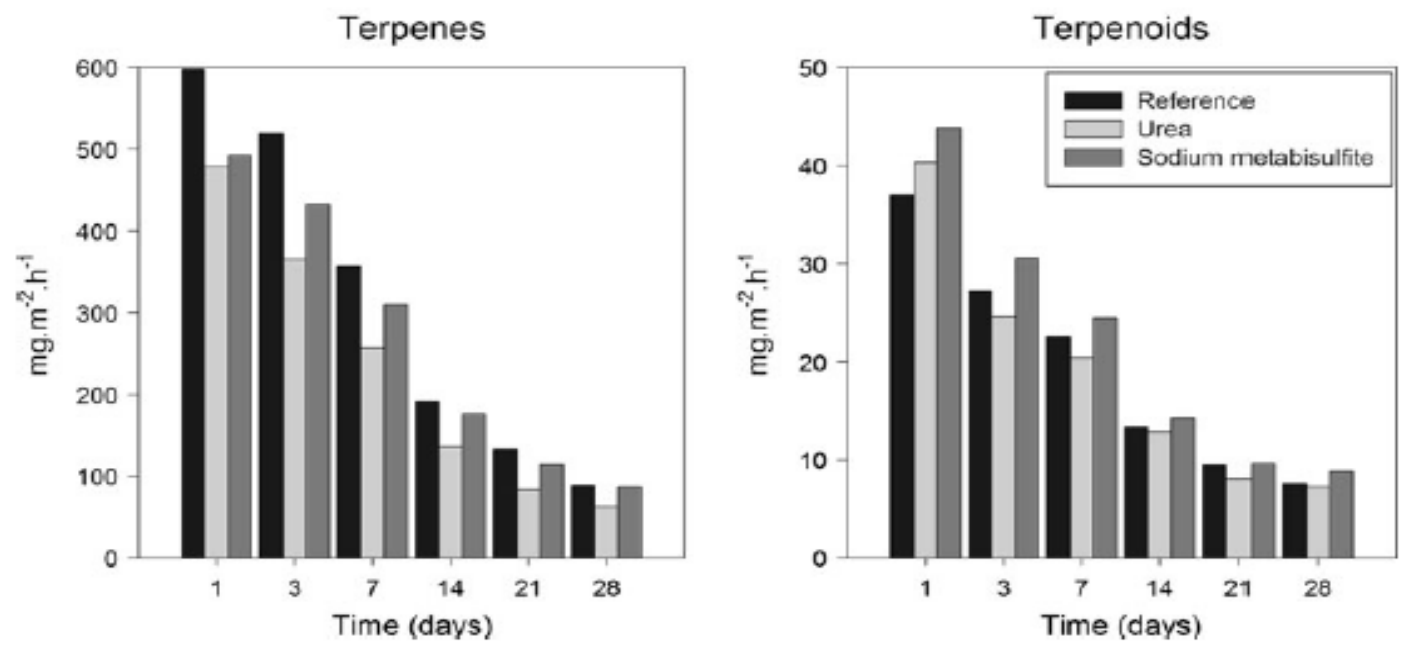

Fig. 1 Amount of VOC (aldehydes, acids, terpenes and terpenoids) emissions from boards made from Maritime pine (Pinus Pinaster Ait.)

Terpenes are the main source of VOCs from the parti-cleboard made from pine, being these extractives responsible for its characteristic odour (Makowski and Ohlmeyer 2005). Terpenes from pine are mainly longifolene, $\alpha$-pinene and caryophyllene, corresponding to more than 90 $\%$ of the terpene emission after the 7 th day. In the first days, emission of $\beta$-pinene, limonene and terpinolene can also be found. Terpenoids emission is mainly terpineol, despite of some camphor release in the first day. No significant differences can be found when using different scavengers. Other compounds were also released in the first week, such as alcohols, ketones and hydrocarbons (fatty acids and waxes), and no significant differences were found between boards (not shown, but considered in TVOCs).

Figure 2 shows the VOC release from particleboards made from poplar. VOC emissions are mainly acetic acid, but a small amount of aldehydes (hexanal) was also found. In the first week, some release of ketones, alcohols and hydrocarbons was also observed (not shown, but considered in TVOCs). No significant differences were found for particleboards with scavengers, except for the total absence of aldehydes when sodium metabisulphite was used.

A small amount of longifolene (a terpene) emission was found during the first days in the particleboards made from poplar. As stated in literature, terpenes are not usual in hardwoods In this special case, longifolene (a sesquiterpene) is typical for pine and spruce species (Fengel and Wegener 1989), indicating that the presence of this compound could be related to some cross contamination, probably during the collection of wood particles at the industrial plant. Emission of acetic acid when sodium metabisulphite is used (compared with urea) seems to increase. This could be related to the deacetylation of wood by sodium metabisulphite. 

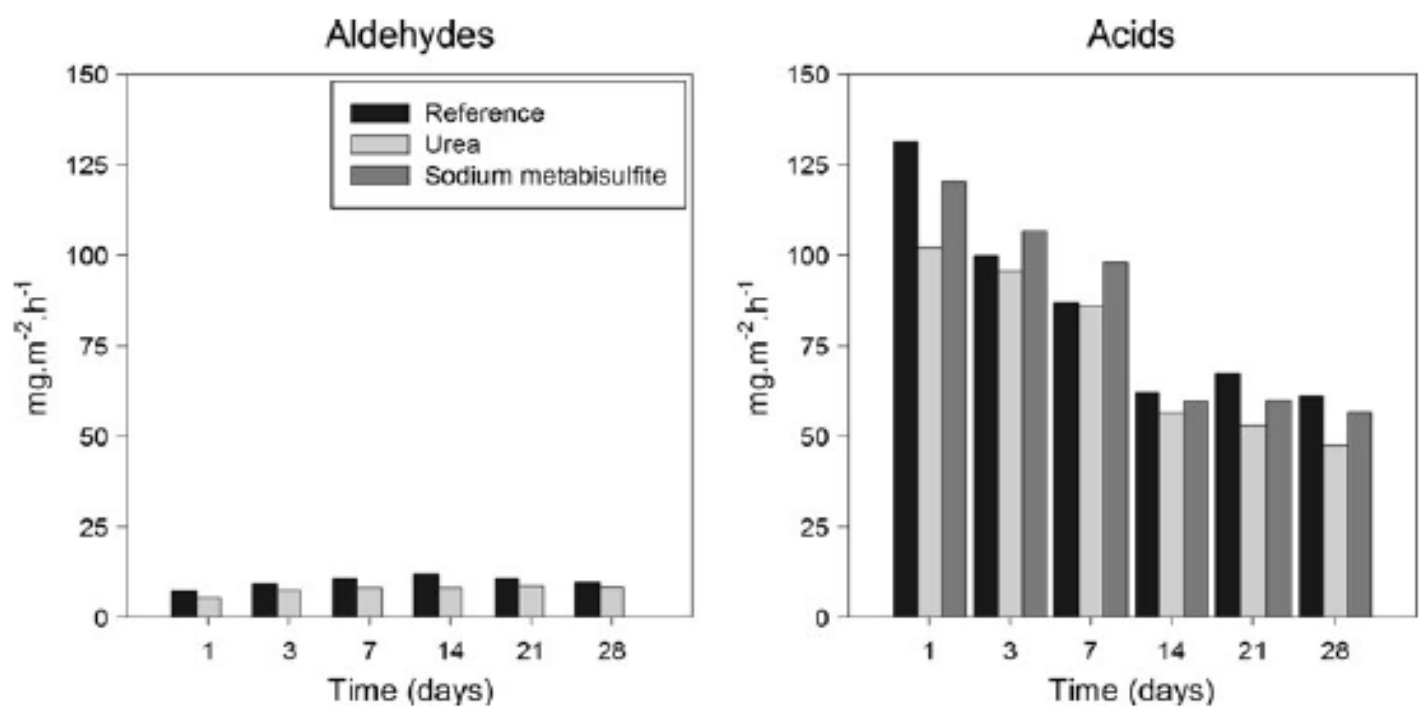

Fig. 2 Amount of VOC (aldehydes and acids) emissions from boards made from poplar

Figure 3 shows the TVOCs emitted from produced particleboards. Differences between boards made from pine and poplar can be clearly observed. Poplar boards present much lower VOC emissions than boards made from pine. Despite some reduction on TVOCs induced by urea during the test period, after 28 days, differences in total emission can be neglected. However, when sodium metabisulphite is used, a substantial reduction in total emission is found. This is mainly caused due to the excellent ability of sodium metabisulphite to scavenge aldehydes.

After 28 days, reduction induced by sodium metabisulphite is more than $40 \%$ while reduction due to addition of urea is lower than $10 \%$. When poplar is used as wood raw material, no significant differences are found in TVOC emissions during the whole testing period. This might be related to the reduced presence of aldehydes.

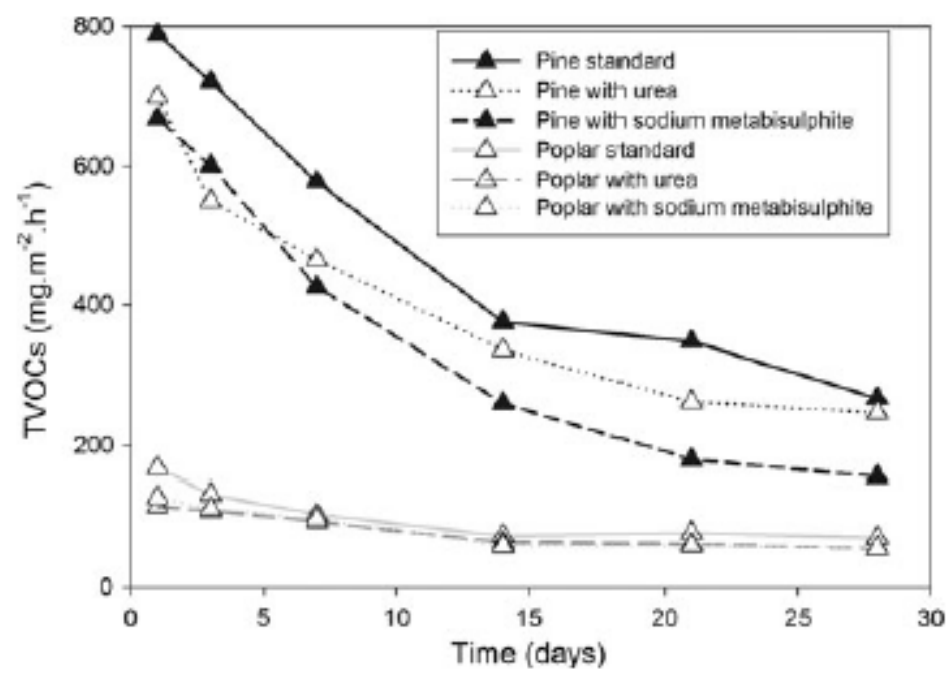

Fig. 3 TVOCs (total volatile organic compounds) emitted from the boards produced 


\section{Conclusion}

VOCs scavenging ability of two formaldehyde scavengers (sodium metabisulphite and urea) was tested using two different wood species: maritime pine (Pinus Pinaster Ait.) and poplar (Populus spp.). Particleboards were produced using a low formaldehyde emission UF resin and characterized according to EN ISO 16000.

TVOC emissions from particleboards made from poplar are nearly $25 \%$ smaller than emission from pine. Boards made from pine emit higher amount of terpenes, acids as well as aldehydes, while boards made from poplar emit mainly acetic acid. Addition of urea did not affect TVOCs, while sodium metabisulfite reduced more than $40 \%$ of total emission of boards made from pine. When applied to boards made from poplar, reduction was negligible due to the lower emission of aldehydes. Sodium metabisulphite is an excellent aldehyde scavenger and is able to reduce substantially TVOCs from wood-based panels, when soft-woods are used as raw-materials.

\section{References}

AIMMP (2013) Industrial uses of maritime pine (in Portuguese). Association of Portuguese Wood and Furniture Industries. Available at http://www.aimmp.pt/. Accessed Jan 2013

Carvalho A (1997) Portuguese wood species (in Portuguese), vol 2.

Direç̃̃ Geral das Florestas

Costa N, Pereira J, Ferra J, Cruz P, Moreira J, Martins J, Magalhã es F, Mendes A, Carvalho L (2012) The role of sucrose in amino polymers synthesized by the strongly acid process. J Adhes Sci Technol 27(7):763-774

Costa N, Pereira J, Ferra J, Cruz P, Martins J, Magalhã es F, Mendes A, Carvalho L (2013a) Scavengers for achieving zero formal-dehyde emission of wood-based panels. Wood Sci Technol 47(6):1261-1272

Costa N, Pereira J, Ferra J, Cruz P, Martins J, Magalhã es F, Mendes A, Carvalho L (2013b) Sodium metabisulfite as a scavenger of air pollutants for wood-based building materials. Int Wood Prod J 4(4):242-247

Despres A, Pizzi A, Vu C, Delmotte L (2010) Colourless formaldehyde-free urea resin adhesives for wood panels. Eur J Wood Prod 68(1):13-20

ECA Report No. 18 (1997) Evaluation of VOC emissions from building products. Office for Official Publications of the European Communities, Brussels

EN ISO 16000-6 (2011) Indoor air-Part 6: determination of volatile organic compounds in indoor and test chamber air by active sampling on Tenax TA sorbent, thermal desorption and gas chromatography using MS or MS-FID

EN ISO 16000-9 (2006) Indoor air-Part 9: determination of the emission of volatile organic compounds from building products and furnishing-Emission test chamber method 
Eom Y-G, Kim J-S, Kim S, Kim J-A, Kim H-J (2006) Reduction of formaldehyde emission from particleboards by bio-scavengers. MokchaeKonghak 34:29-41

Fengel D, Wegener G (1989) Wood: chemistry, ultrastructure, reactions. Walter De Gruyter Inc, Berlin

Ferra J, Mena P, Martins J, Mendes A, Costa M, Magalhã es F, Carvalho L (2010) Optimization of the synthesis of urea- formaldehyde resins using response surface methodology. J Adhes Sci Technol 24(8-10):1455-1472

Fischer M, Aehlig K (2007) Emission of VOC from wood and wood products - two case studies. In: COST Action E49 Conference on Measurement and Control of VOC Emissions from Wood- Based Panels. Braunschweig, Germany

Hodgson A, Beal D, Mcllvaine J (2002) Sources of formaldehyde, other aldehydes and terpenes in a new manufactured house. Indoor Air 12(4):235-242

Kim S (2009) The reduction of indoor air pollutant from wood-based composite by adding pozzolan for building materials. Constr Build Mater 23(6):2319-2323

Kim S, Kim H, Kim H, Lee H (2006) Effect of bio-scavengers on the curing behavior and bonding properties of melamine-formaldehyde resins. Macromol Mater Eng 291(9):1027-1034

Makowski M, Ohlmeyer M (2005) Influences on VOC emissions of wood-based panels. In: 9th European Panel Products Sympo- sium. Llandudno, Wales, UK

Makowski M, Ohlmeyer M (2006a) Influences of hot pressing temperature and surface structure on VOC emissions from OSB made of Scots pine. Holzforschung 60(5):533-538

Makowski M, Ohlmeyer M (2006b) Comparison of a small and a large environmental test chamber for measuring VOC emissions from OSB made of Scots pine (Pinus sylvestris L.). Holz Roh- Werkst 64(6):469-472

Makowski M, Ohlmeyer M, Meier D (2005) Long-term development of VOC emissions from OSB after hot-pressing. Holzforschung 59(5):519-523

Martins J, Pereira J, Pinto B, Coelho C, Carvalho L (2007) Effect of recycled wood on formaldehyde release of particleboard. In: COST Action E49 Conference on Measurement and Control of VOC Emission from Wood-Based Panels. Braunschweig, Germany

Ohlmeyer M, Makowski M, Fried H, Hasch J, Scholer M (2008) Influence of panel thickness on the release of volatile organic compounds from OSB made of Pinus sylvestris L. For Prod J 58(1-2):65-70

Paiva N, Henriques A, Cruz P, Ferra J, Carvalho L, Magalhães F (2012) Production of melamine fortified urea-formaldehyde resins with low formaldehyde emission. J Appl Polym Sci 124(3):2311-2317

Prasittisopin L, Li K (2010) A new method of making particleboard with a formaldehyde-free soy-based adhesive. Compos A Appl Sci Manuf 41(10):1447-1453 
Risholm-Sundman M, Lundgren M, Vestin E, Herder P (1998) Emissions of acetic acid and other volatile organic compounds from different species of solid wood. Holz Roh-Werkst 56(2):125-129

Steckel V, Welling J, Ohlmeyer M (2010) Emissions of volatile organic compounds from convection dried Norway spruce timber. In: COST Action E53 Conference on The Future of Quality Control for Wood \& Wood Products. Edinburgh, Scotland

Tang L, Zhang Z, Qi J, Zhao J, Feng Y (2011) The preparation and application of a new formaldehyde-free adhesive for plywood. Int J Adhes Adhes 31(6):507-512 
